\title{
A Proposal for a Northeastern Regional Library
}

Dr. Metcalf is director, Harvard University Library.

D R. WHITE's paper was very interesting, and provides a good background for what I have to say. I do not think that we are very far apart in most respects and, in the places where we may seem to disagree, I hope you will keep in mind these three points :

I. The ideas and plans that I shall state are not original with me.

2. I am ready to change them at any time if that is what other librarians want; but

3. I do want a regional library in which the great libraries of the northeastern states will cooperate.

I should try to start at the beginning by picturing the way we have been thinking on the subject at Harvard and, I believe, at Yale, too. Please remember that Harvard will have more than $5,500,000$ volumes and pamphlets in its library by sometime next year, and that it is spending on its library the income of well over $\$ 40,000,000$-something like $\$ \mathrm{I}, 750$,000 a year-which makes a very appreciable hole in the university's total endowment. Harvard is ahead of the others at present, but not very far. It is 65 years older than Yale and 10 to 12 years ahead in the size of its library. All of us are growing rapidly enough to cause great concern.

This great size has come by geometric growth, which we do not seem able to stop completely, though it may be fair to say that

1 Paper presented at the meeting of the New York Library Association, New York City, April 29, r950. some progress has been made. This growth at Harvard and other research institutions has made library expenditures tend to increase more rapidly than those of other parts of the university, chiefly because of costs of building construction and upkeep. We probably should have realized this a generation or so ago, but we failed to see how serious it was because we were then living through a remarkable building era. Because of inflation, we now feel it more sharply than would normally be the case.

The gravity of the situation in many universities can be described bluntly: If libraries continue to grow as in the past, and if we have a reasonably stable economy and income, one or more professors will have to be dropped each year in order to keep the library going. This is certainly intolerable and cannot be defended if we are now spending enough for our libraries. We must decide what percentage of total expenditures the library should take, and try to stick to that figure. We shall have to find a way out of our dilemma.

This situation brought about the New England Deposit Library, which has been successful in every way but one. It has not succeeded in eliminating duplicates already acquired by the cooperating libraries or in reducing duplication of current acquisitions as had been hoped. The reason for this failure, we believe, is that the larger libraries, which occupy some fourfifths of the space in the New England Deposit Library-the Massachusetts State Library, the Boston Public Library, and 
Harvard-are different in character; their collections as a whole, and therefore their less-used books, tend not to overlap. Consequently it has seemed to those who were particularly interested that, if a cooperative storage library is to do more than provide cheap storage space, it should include a considerable number of large general research libraries owning little-used collections that would overlap. There is no one place in the Northeast where you can find many such collections. New York City, Boston and Philadelphia have tremendous concentrations of book resources, but it takes a whole region to provide enough large general research libraries to make a start. Harvard, Yale, Columbia, the New York Public Library, Princeton, and Pennsylvania have some $\mathrm{I} 7,500,000$ volumes in all, and there must be a great amount of duplication in the collections already owned and in current acquisitions of bulky, littleused materials. Because they contain a large proportion of the duplicated littleused books to be found in northeastern libraries, they seem to be the best with which to start; the last meeting, to which Dr. White referred, included representatives of these six libraries plus Cornell, the only other general research library in the section with more than a million volumes, and the Library of Congress:

The first step in our thinking, then, was that the library we had in mind must cover the whole region to be really worth while. Now, before we go on with the proposal, let me insert a basic principle of library philosophy and administration that we have held at Harvard and that affected our thinking and planning. We believe that one of the great difficulties in all libraries is that they get too complicated. We also believe that one of the obstacles to starting anything new in libtaries is that the original plan tends to be too complicated. Because we believe this at Harvard, our cataloging is simpler than in most other places and probably, as a result, unorthodox. We give less reference service than most other libraries. Our charging systems are kept as simple as possible. We even like to use simple words-instead of saying "cubicle" in three syllables or "carrell" in two, we use monosyllabic "stalls." An example of an attempt to avoid complexity in a new proposal is the Farmington Plan, which has now been operating for more than two years. It is a noble experiment, as was said of prohibition. It has not always run smoothly. It is very easily criticized. It does not, for instance, include periodicals and other serials, which are the most important research materials in many subject fields. It does not include books in nonLatin alphabets despite the importance of Russia in the world today. But, if it works at all and if it gradually improves, that may well be because it has not tried to do everything at once.

We started, as I have said, with the belief that we ought to have a cooperative library covering the whole region to help us take care of our less-used, bulky collections and to eliminate unnecessary duplication, and we thought that the plans with which we started ought not to be too complicated. After his assistant, Edwin E. Williams, had visited the large libraries concerned, the speaker made a tentative proposal to serve as a basis for discussion by the eight libraries that have been named. It includes the following points, which have been revised since the January meeting in an attempt to make them reflect the thinking of the group at that time:

I. It is suggested that the institutions mentioned above take the lead in forming the proposed library, but that they welcome others (principally large research libraries) that may care to join them. This proposal has been criticized as too exclusive. I see no reason why small as well as large libraries should not cooperate in the plan if they are ready to pay their share of the costs. 
It should be remembered, however, that the large libraries will benefit most by eliminating duplication both of material already acquired and of unnecessary, little-used acquisitions in the future. They will have the most to contribute and the most to gain, but I see no reason for excluding smaller institutions.

2. It is proposed that the library be called the Northeastern Regional Library, as that name covers the Middle Atlantic and New England states and makes it clear that the institution is a regional library. A longer name seems unnecessary and undesirable.

3. The library should have a charter providing for tax-exemption and making it possible for the cooperating libraries to place books there under conditions proposed below. In order to obtain such a charter, legal advice should be sought as to its contents and the best place to obtain it.

4. The selection of books for the regional library is a major problem. It is suggested as a basis for discussion that much of the material sent in the original selection be from the fields in which the materials are bulky and in which no one of the libraries has a really great collection, but in which the combined resources might be superior to any now to be found in this country and important enough to attract scholars. These collections might be of widely different types; first of all (probably less important than some others in the long run, but of special importance in getting started) would be material that is now a problem because it requires a good deal of space and is not much used. Cooperative purchase might not be involved here. The following categories are suggested:

(a) Textbooks, particularly secondary and elementary school textbooks. If a number of the libraries sent those published in the United States between 1820 and the comparatively recent past (if not the present), the combined collections would provide many duplicates for discarding or shipping to another regional library, and would form a better collection than can now be found anywhere in the country. (Harvard has about 50,000 volumes that it would seriously consider sending.)

(b) Administrative publications of colleges, universities, and schools. If the great bulk of these could be placed under one roof, it would create a great collection and eliminate many duplicates.

(c) Dogmatic theology and Bibles published after I 8oo. Scholars should find it useful to have a single large collection.

(d) Old books on the physical sciences and medicine that are out of date and of little importance in connection with the history of these fields.

(e) Old editions of Greek and Latin classics, particularly nineteenth century editions from other countries.

(f) Translations from one modern language into a second other than English.

(g) Juvenile literature published after I 840 .

(h) Minor fiction by English, American, French, and German authors.

A second type of material, one that in the end might be more important than the first, consists of bulky collections that are difficult to keep up to date and that probably do not need to be duplicated within the area. Two important categories can be suggested in this group:

(a) Public documents from American states and municipalities; foreign municipal documents; and foreign national documents except those of Great Britain, Canada, Germany, France and Russia. Each library might keep the state documents for its own region and for certain other states or countries on which it has special collections, but, if material of this kind could be gathered in one place, the resulting collection would be far superior to anything that can be found at present except, possibly, in the Library of Congress and the New York Public Library. These document sets should of course be kept up to date, and there would be a great saving if this were 
done only at the regional library. Files would be maintained at just one place, and a better job could be done there than is now done in any library other than the $\mathrm{Li}$ brary of Congress.

(b) Serial publications, including periodicals of various kinds. These would include journals of learned societies and other publications used chiefly for advanced research in which not very many individuals would be engaged. There would be great savings in money and space if collections of this type from half a dozen large research libraries could be combined, if duplicates were eliminated, and if the files were then kept up in a regional library.

A third major class might be constituted by the Farmington Plan acquisitions of libraries in this section. It has been suggested that research libraries in the Northeast ought, between them, to acquire one copy of most of the Farmington books, even if other copies are to be found further west or south.

Rarities, presumably, would be retained by the libraries that own them, but a number of special collections seem to be suitable for deposit, among them:

(a) Collections in minor languages, particularly when two or more of the cooperating libraries have fairly strong little-used collections and when consolidation would make a great collection. (For example, the Friesian collections at the New York Public, Pennsylvania, and Harvard, and the Icelandic collections at Cornell, Harvard, the New York Public, and Yale.)

(b) Broken sets of any periodical when combination of files would produce a complete or more nearly complete run than can now be found in any single library.

(c) Books on nonacademic subjects such as sports and games, "pseudosciences," and shorthand.

(d) Patents, foreign dissertations, trade catalogs, and certain kinds of legal material are also possibilities.

5. It is proposed that material sent to the regional library be on permanent deposit. The decision on this point is vital because the permanent withdrawal of a deposited book after other copies had been discarded would seriously complicate matters. (The question of transferring legal title could still, of course, depend on the wishes of the individual cooperating libraries.)

6. The next problem is the kind of installation that should be provided. How much land ought to be acquired? If a country location is chosen, it might be proper to obtain more land than would be acquired in a city, and this would provide room for more or less indefinite expansion. Wherever it is located, the building should be erected on a unit plan that would facilitate enlargement. It should certainly include:

(a) A large amount of cheap shelving for book storage.

(b) A shipping room, work room, office space, and toilet facilities.

(c) A station wagon and a truck should probably be provided as part of the original equipment.

But other questions arise here. Should there be a reading room, or are the books to be used only when borrowed by other libraries? Will the library have to buy and catalog reference books? Will any other facilities, such as a lunchroom and even sleeping accommodations, be required? These questions cannot be decided until the location has been determined. It may well be that we have gone far enough by making the proposals already listed, and that there should be no discussion of possible locations for fear it will complicate the problemsomething that I said is undesirable-and because it might stir up discussions that would make cooperation more difficult in the future. It seems to me, however, that this question is so basic that it should be considered at an early stage. Here I can speak only for myself. F have made a proposal that some of you know about, and I can at least explain what went through my 
mind before I made it.

Other things being equal (which, of course, they are not), I should say without hesitation that there are two essentials in choosing a location :

(a) It should be as central as possible and convenient to the largest possible number of persons among those who will want to use the library.

(b) The new institution should be attached to a great library already in existence, and preferably under the same roof. The complications that arise when a library is set up at a distance from a good reference collection are shown by the experience of the Huntington Library in California, the Roosevelt Library at Hyde Park, and many others.

With these two essentials in mind, I think we should all agree that the proper place for the Northeastern Regional Library would seem to be at 42 nd Street and Fifth Avenue, New York. Unfortunately, we know that the New York Public Library building is full already and that, even if funds could be obtained for adding to that building, there would not be room for the millions of books that will, we hope, be located in the regional library within a generation. There seems to be no prospect that the City Park Commissioner will allow us to build a regional library in Bryant Park, and the cost of other land in the neighborhood would certainly be prohibitive. Apparently this ideal location will have to be abandoned.

Now I come to a problem about which I hesitate to speak because it probably shows my own smallness and the smallness that I attribute to other members of my profession and, for that matter, to the academic world in general. Why not attach the Northeastern Regional Library to one of the great university libraries in the section? The three most centrally located ones are Columoia, Yale, and Princeton. I do not believe that the Yale faculty and administrationleaving the library out of consideration- or the Columbia faculty and administration, or the Harvard faculty and administration would agree any time within the next Io years to transfer a large part of its library book collections to the campus of one of the other university libraries, and we might just as well admit it. Some have suggested that we work out an exchange, sending for instance all documents to one library, all Swedish books to another, etc. Again, I am afraid it would not work, and for the same reason. In addition, it should be remembered that one of the chief reasons for talking about this regional library is that space on a college campus is so expensive. Buildings there must be of high quality, land is not plentiful, and costs tend to rise unduly. If, then, it seems impossible to have the library in or closely attached to the New York Public Library at 42nd Street and Fifth Avenue, and if we are agreed (I still admit in spite of what I have said that this is a debatable matter) that it should not be on the campus of one of the present libraries, where should it be? Again, we come back to my original proposition that it should be as conveniently located as possible, but the cost should be kept in mind. New York City is certainly central for the whole Northeast, but almost any land near the heart of the city is expensive, and to acquire space sufficient for indefinite expansion would be very costly. If we go out to the edges of the city -to Staten Island, the northern Bronx, or the eastern part of Queensborough, to say nothing of north Jersey-we can avoid some of the expense, and these locations certainly ought to be considered. I have suggested, however, a location near the Merritt Parkway north of Stamford in the belief that it would be more convenient to most users than any place that could be found in an out-of-the-way part of New York City. Most of the books and most of the users are likely to come from institutions and locations having ready access to the railroad from Washington to Boston 
and to the super-highway that runs, or soon will run, from the vicinity of Philadelphia to Boston. This would seem to suggest that the library, if it is not to be located in the heart of New York City or immediately adjacent to one of the university libraries, should be fairly close to either the Pennsylvania or the New York, New Haven and Hartford Railway. I have no ax to grind for Stamford, and any other equally convenient place, if agreed upon by the others, would suit me just as well. What have you to suggest?

It may be worth while to recapitulate a few points that ought to be considered in choosing a location:

(a) Land in a large city is expensive except on the outskirts, which may well be as difficult of access as a country location.

(b) Costs in general are apt to be higher in a city than elsewhere.

(c) City atmospheric conditions make air conditioning desirable, but it is expensive.

(d) It is difficult to arrange for indefinite expansion in a city.

(e) A location beside or in one of the cooperating libraries is certain sooner or later to cause jealousy. This, I am afraid, has already proved to be one of the most serious problems facing the Midwest Interlibrary Corporation. A city location not close to an existing library has little to recommend it.

(f) A city location may be less safe in an atomic age than one in the country.

(g) A city location will attract unnecessary and perhaps undesired use, which might add considerably to the cost of the whole operation.

(h) The Midwest Inter-library Corporation is in a great city and adjacent to a great library; it may be worth while to experiment with a different plan for the Northeastern Regional Library, and the fact that it is different might make it easier to finance the proposed library.

Let us now go back to the type of in- stallation. When we have decided where to build, the question will come up as to whether the library should contain a reading room or should require that books be used only in the cooperating or other libraries. Again, it is easy to argue on either side. I should hesitate to advocate a reading room if the library were anywhere within five miles of 42 nd Street and Fifth Avenue, because of the users who might be attracted and resultant costs. On the other hand, if the library were to be at Stamford, I should feel strongly that a scholar who came and wanted to work intensively in a field covered by the collection ought to be able to do so in a reading room close to the books he would be consulting. But this raises a new problem. If the library is to be in the country and is to have a reading room, then restaurant facilities and perhaps sleeping accommodations also must be provided. With this in mind, my suggestion included a guest house for users of the library as well as a lunchroom, and I even proposed that during the first few years the guest house might well include quarters for the librarian and possibly some members of the staff.

One of the most complicated and difficult problems that a regional library would have to face is cooperative or centralized buying and cataloging. I have suggested as a basis for discussion that, while it would be a mistake to say that cooperative acquisition and cataloging should never be developed at the Northeastern Regional Library, it might be unwise to include either in the original plan, or as an integral part of the proposal. The enterprise is intricate enough without. But I did suggest that an exception might be made for Farmington Plan books-if the cooperating libraries were willing to have their Farmington Plan books sent there these might be cataloged at the expense of the regional library. There may be great advantages in such a procedure for Farmington books from countries using "minor" languages. 
I must add - and this is another debatable question-that there are surely good grounds for the feeling of Dr. White and of Mr. Beals of the New York Public Library that the most important part of the regional library will be its acquisition program for bulky collections of documents, periodicals, etc., and I think the decision should be made by the cooperating libraries and certainly not by Keyes Metcalf.

The points that have been raised are important, as are many others that might be considered. There can be arguments on either side, but many of the final decisions will probably have to be made on the basis of costs. Expenditures in carrying out the proposal would fall naturally into the following categories:

(a) The original cost of the land, the building, and other essential equipment.

(b) The cost of sending the first shipments from the cooperating libraries to the Northeastern Regional Library.

(c) The current expenses for service in the library, including the use of the collections, physical care of the building, the guest house (if one is provided), and the automobile.

(d) The cost of servicing interlibrary loans.

(e) The cost of additions to the building as time goes on.

(f) The cost of any cooperative acquisition of cataloging that is done.

I have made some rough estimates for each of these. The original plant might well cost $\$ 1,000,000$. I have suggested that the regional library try to finance the cost of shipping the first million volumes to it, pointing out that it would go a long way toward giving the library a good start if $\$ 100,000$ could be provided for this, because libraries would hurry up their shipments in order to take advantage of the offer. I have estimated the cost of current expenses at $\$ 55,000$ per year. The actual figure will depend very largely in the long run on whether the staff is simply a service staff or must also undertake acquisition and cataloging. The figure will grow rapidly in the latter case.

Also as a basis for discussion, I suggested that service charges for use of the collection might be agreed upon, and proposed a scale of charges to cover interlibrary loan expenses.

I betieve that the cost of additional units of the building when they are needed will be a serious problem and should not be overlooked when making the original plans.

The figures that have been indicated for expenditures run very high, and I think it only fair to admit that three or four million dollars should be available or in sight if the library is to go ahead on the scale proposed. Where can the funds be obtained? There seem to be four possible sources:

(a) One or more of the philanthropic foundations.

(b) Individuals who, whether or not they now have any affiliation with a university or research library, may be interested in library development and in solving the problem of geometric growth of libraries.

(c) The cooperating institutions.

(d) Governmental agencies-the Federal government, either directly or through the Library of Congress, and, as Dr. White has suggested, possibly an interstate library authority for the region.

All of these should be explored. None of them can be expected to help unless there is a reasonable agreement on the plan by the libraries concerned, and it is therefore of great importance that there be thoroughgoing discussion of the various points on which disagreement may arise. I hope the debate will be full and free; as I said at the beginning, I should like you to remember that this is not my plan and that $I$ am ready to have changes made in it, but that I do want a regional library for the Northeast. 